\title{
NOTE \\ Internal Medicine \\ Long-term management and postmortem examination in a diabetic cat with acromegaly treated with two courses of radiation therapy
}

\author{
Harumi SAWADA ${ }^{1)}$, Akihiro MORI ${ }^{2) *}$, Masaki MICHISHITA ${ }^{1)}$, Hitomi ODA ${ }^{2)}$ and \\ Toshinori SAKO ${ }^{2)}$ \\ ${ }^{1)}$ School of Veterinary Science, Faculty of Veterinary Science, Nippon Veterinary and Life Science University, \\ 1-7-1 Kyonancho, Musashino, Tokyo 180-8602, Japan \\ ${ }^{2)}$ School of Veterinary Nursing \& Technology, Faculty of Veterinary Science, Nippon Veterinary and Life Science \\ University, 1-7-1 Kyonancho, Musashino, Tokyo 180-8602, Japan
}

\section{J. Vet. Med. Sci.}

81(1): 71-76, 2019

doi: 10.1292/jvms.17-0289

\section{Received: 29 May 2017}

Accepted: 7 November 2018

Published online in J-STAGE:

16 November 2018
ABSTRACT. A 12-year-old, castrated male cat with diabetes mellitus was diagnosed with acromegaly and examined with magnetic resonance imaging (enlarged pituitary gland, $8 \mathrm{~mm}$ ); serum hormone concentrations were measured. After the first course of radiation therapy (4 Gy, 12 fractions), insulin administration was not required from day 420 after diagnosis. Enlarged pituitary tumor $(8 \mathrm{~mm})$ recurred, and insulin dosage amount of the cat was increased on day 1,065. The second course of radiation therapy (6 Gy, 4 fractions) was performed on day 1,201 and insulin administration was again discontinued. However, the cat died from lymphoma on day 1,397. Postmortem examination revealed pituitary adenoma. Most tumor cells were positive for chromogranin A, synaptophysin, and growth hormone immunohistochemistry. The pancreatic islet cells revealed diffuse hyperplasia. We achieved long-term successful management of an acromegalic cat with two courses of RT. However, a protocol for a second course of RT for feline recurrent pituitary tumor should be further discussed.

KEY WORDS: acromegaly, diabetes mellitus, growth hormone, insulin-like growth factor-1, radiation therapy

Feline insulin resistance is defined as persistent serum hyperglycemia regardless of adequate insulin injection dosage ( $>1.5 \mathrm{IU} /$ $\mathrm{kg}$ ) [6]. In diabetic cats, concurrent diseases that cause the most severe insulin resistance are acromegaly and hyperadrenocorticism [6]. Feline acromegaly is induced by overproduction of growth hormone $(\mathrm{GH})$ from pituitary tumors. GH and insulin-like growth factor-1 (IGF-1), which are produced by the liver and stimulated by GH, induce insulin resistance by competing for insulin receptors $[6,7,13,17]$. Treatment for feline acromegaly has been widely reported, and radiation therapy (RT) is known to be effective $[2,8,10]$. In this report, we successfully managed a cat with acromegaly during the disease period ( $>3$ years) with two courses of RT, and we also report the postmortem examination of the cat.

A 12-year-old, castrated male, domestic shorthair cat weighing $4.75 \mathrm{~kg}$ was presented to the local veterinary hospital on day26. The cat showed anorexia, depressed consciousness, and collapse. Furthermore, swelling in the head and paws was observed by inspection and palpation. Abdominal ultrasound revealed hepatomegaly; however, other abdominal findings were normal. No abnormalities, including heart enlargement or valvular disease, were observed on echocardiographic examination. Serum biochemistry results showed elevated fasting hyperglycemia $(412 \mathrm{mg} / \mathrm{d} l)$ and hypertriglyceridemia $(1,098 \mathrm{mg} / \mathrm{d} l)$. Serum glycated albumin (GA) was $21.7 \%$, indicating an early diagnosis of diabetes mellitus [12]. Urinalysis revealed high glucose concentration, ketonuria, and high specific gravity (>1.050). Blood gas analysis revealed a $\mathrm{pH}$ of 7.29 and $\mathrm{HCO}_{3}{ }^{-}$of $12.5 \mathrm{mmol} / l$ (GEM Premier 3000 Blood Gas Analyzer, IMI Co., Ltd., Saitama, Japan). Diabetic ketoacidosis was diagnosed based on clinical symptoms and blood and urine test results. Insulin therapy (Lantus, Sanofi Aventis, Tokyo, Japan) was then started, and although the dosage was gradually increased from $4 \mathrm{IU} / \mathrm{kg}$ twice daily, hyperglycemia did not resolve; therefore, the dosage was gradually increased to 20 $\mathrm{IU} / \mathrm{kg}$ twice daily with daily home monitoring of glucose on day 1 (Fig. 1).

On day 1, the cat was transferred to Nihon University Animal Medical Center (Fujisawa, Japan) to investigate the cause of severe insulin resistance. Physical examination revealed a body weight of $5.3 \mathrm{~kg}$, temperature of $38.8^{\circ} \mathrm{C}$, heart rate of $168 \mathrm{beats} /$

*Correspondence to: Mori, A.: amori@nvlu.ac.jp

O2019 The Japanese Society of Veterinary Science

This is an open-access article distributed under the terms of the Creative Commons Attribution Non-Commercial No Derivatives (by-nc-nd) License. (CC-BY-NC-ND 4.0: https://creativecommons.org/licenses/by-nc-nd/4.0/) 


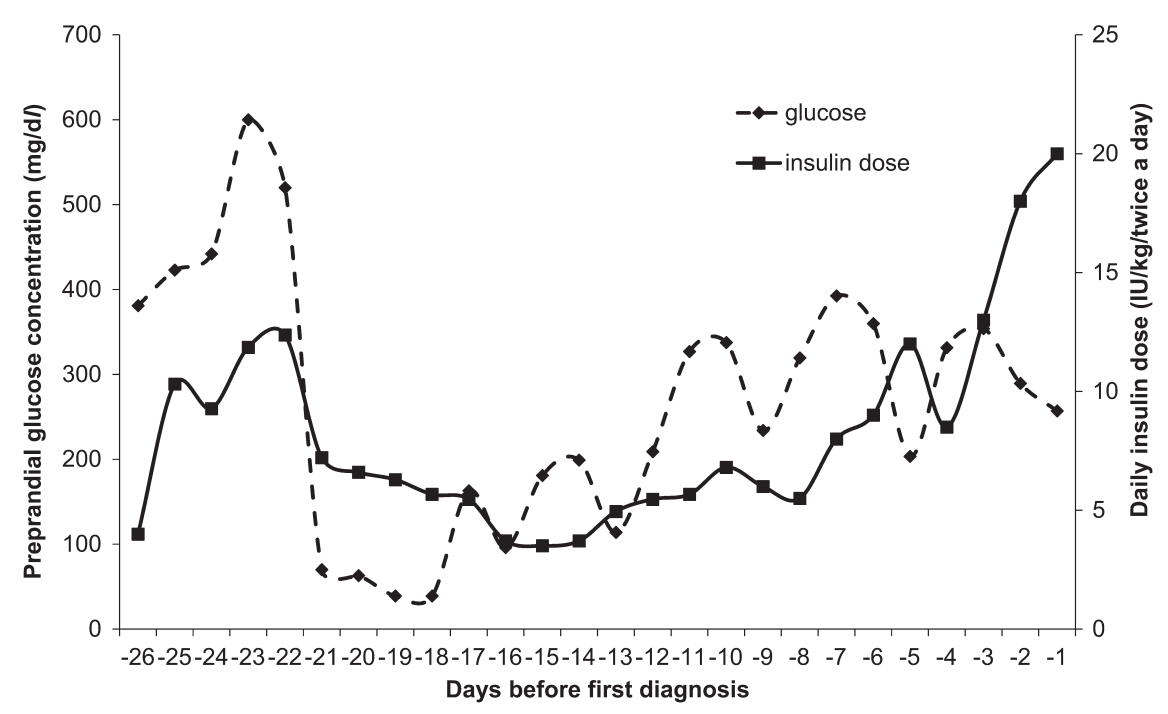

Fig. 1. The change in serum preprandial glucose concentrations $(\mathrm{mg} / \mathrm{d} l)$ (left y-axis, dashed line) and daily insulin dose (IU/kg twice daily) (right y-axis, solid line) in the cat during day-26 to day-1.
Table 1. Clinical test results of acromegalic cat

\begin{tabular}{llc}
\hline \multicolumn{1}{c}{ Parameters } & Units & day 1 \\
\hline Complete blood counts & & \\
Red blood cells & $/ \mu l$ & $7.90 \times 10^{6}$ \\
Hemoglobin & $\mathrm{g} / \mathrm{d} l$ & 11.5 \\
Hematocrit & $\%$ & 32.0 \\
Platelet & $/ \mu l$ & $14.9 \times 10^{4}$ \\
White blood cells & $/ \mu l$ & 12,260 \\
\hline Blood biochemical test & & \\
Glucose & $\mathrm{mg} / \mathrm{d} l$ & 365 \\
Total protein & $\mathrm{g} / \mathrm{d} l$ & 7.6 \\
Albumin & $\mathrm{g} / \mathrm{d} l$ & 3.3 \\
Aspartate aminotransferase $\mathrm{IU} / l$ & 28 \\
Alanine aminotransferase & $\mathrm{IU} / l$ & 33 \\
Alkali phosphatase & $\mathrm{IU} / l$ & 48 \\
Total cholesterol & $\mathrm{mg} / \mathrm{d} l$ & 136 \\
Triglyceride & $\mathrm{mg} / \mathrm{d} l$ & 112 \\
Blood urea nitrogen & $\mathrm{mg} / \mathrm{d} l$ & 24 \\
Creatinine & $\mathrm{mg} / \mathrm{d} l$ & 1.2 \\
Calcium & $\mathrm{mg} / \mathrm{d} l$ & 11.3 \\
Sodium & $\mathrm{mEq} / l$ & 148 \\
Potassium & $\mathrm{mEq} /$ & 3.9 \\
Chloride & $\mathrm{mEq} / l$ & 119 \\
Glycated albumin & $\% /$ & 21.7 \\
\hline
\end{tabular}

min. Complete blood cell counts, serum biochemistry results recorded on day 1 are shown in Table 1. Severe insulin resistance was considered in the differential diagnosis of hyperadrenocorticism or acromegaly. Adrenocorticotropic hormone (ACTH) stimulation tests were performed, and serum cortisol concentrations were within normal ranges (9.38 before and $11.0 \mu \mathrm{g} / \mathrm{d} l 1 \mathrm{hr}$ after ACTH stimulation test) (IMMULITE 1000, Mitsubishi Chemical Medience Corp., Tokyo, Japan). No abnormal findings of the adrenal gland were seen on abdominal ultrasound, excluding hyperadrenocorticism. Serum GH concentration was $23 \mathrm{ng} / \mathrm{ml}$, and reference intervals for GH were 0.5-3.0 $\mathrm{ng} / \mathrm{m} l$ at FUJIFILM Monolith Co., Ltd. (Tokyo, Japan) (processed by IMMULITE 1000 using the chemiluminescence enzyme immunoassay method; Siemens Immulite GH2, Siemens Healthineers Japan, Tokyo, Japan). Serum IGF-1 concentration was $651 \mathrm{~nm}$ at FUJIFILM Monolith Co., Ltd. (reference range: mean, 48.14; standard deviation, 25.26; n=15) (processed by gamma counter using an immunoradiometric assay kit; IGF-1 IRMA Daiichi, Fujirebio Inc., Tokyo, Japan). Thus, elevated GH and IGF-1 concentrations suggested that acromegaly induced the severe insulin resistance in this case.

Magnetic resonance imaging (MRI) examinations were performed on day 1 to examine the size of the pituitary gland using a 1.5-T scanner and knee coil (EXCELART Vantage, Toshiba Medical Systems Corp., Otawara, Japan). Based on MRI findings, we diagnosed the cat with pituitary tumor $(8.0 \mathrm{~mm}$ ) without other abnormal cranial findings (Fig. 2A and 2B) and confirmed a diagnosis of diabetes mellitus with acromegaly.

RT was performed to decrease the size of the pituitary tumor and ameliorate insulin resistance using linear accelerator with beam energy 4MV (Primus; Toshiba Medical Systems Corp.). RT planning was performed based on CT scan (Aquilion 16; Toshiba Medical Systems Corp.). The cat was positioned (prone) with a customized tooth form device and a vacuum-mattress immobilization device. Treatment plan was generated with a three-dimensional CT-based computer treatment planning system (XiO; ElektaJapan, Tokyo, Japan). Gross tumor volume (GTV) was defined on CT images. Planning target volume (PTV) was defined on expanding $5 \mathrm{~mm}$ margin of GTV. The dose-volume histogram constraints for the organs at risk were as follows: mean brain dose of $<20$ Gy. V20Gy and V50\% were 35 and 30\%, respectively. D95 was 48 Gy. The isocenter and beam arrangements were determined by the PTV locations and adjacent critical normal structure. Beam arrangements were determined in three directions $(0,180$ and 270$)$. The linear accelerator was equipped with a multileaf collimator (10 mm leaves), which was used to block adjacent normal tissue. The cat was administered 4 Gy per fraction, delivered to a total dose of 48 Gy with three fraction per week for a total of twelve fractions. Minimum, Maximum and Mean Dose in the GTV were as follow 46.6 Gy, 48.13 Gy and 47.4 Gy. Megavoltage portal imaging was performed prior to treatment to verify the appropriate positioning before first and sixth treatment.

After RT, blood glucose concentration and insulin requirements were gradually decreased with decreasing serum GA level (Fig. 3), and serum GH and IGF-1 concentrations were also gradually decreased (Fig. 4). As observed on MRI examination, the size of the pituitary tumor $(5.0 \mathrm{~mm})$ decreased on day 216 (Fig. 2C and 2D). As a normal glucose concentration was confirmed, remission of insulin administration was achieved on day 420; however, it was resumed on day 635 as hyperglycemia $(237 \mathrm{mg} / \mathrm{d} l)$ recurred. Serum GH concentration was decreased within the reference intervals on days 359, 574, 847, 1,065, 1,157, and 1,218 after RT. No acute adverse effects were observed during RT. However, post-RT late adverse effects (left otitis media) were diagnosed by 

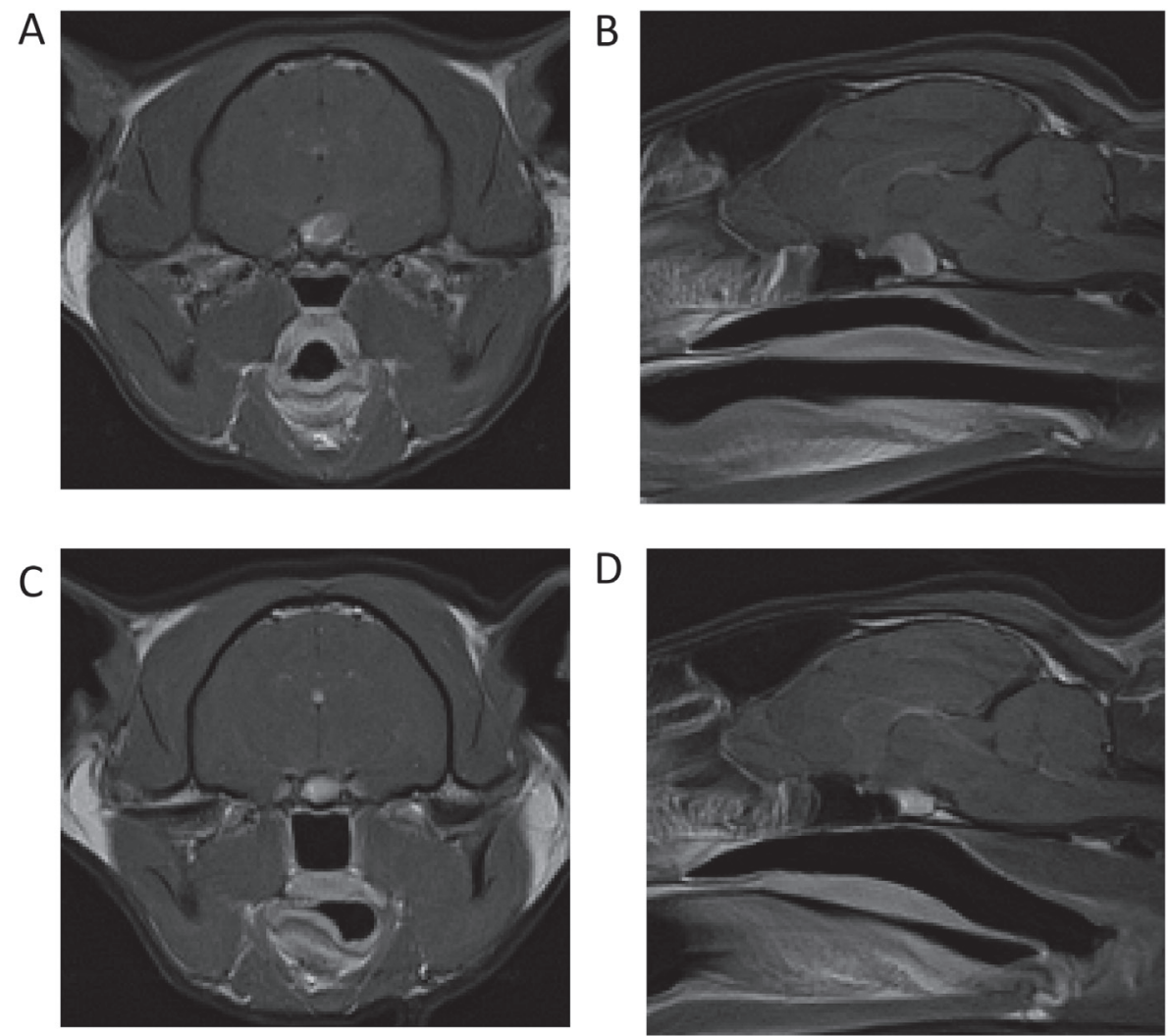

Fig. 2. Magnetic resonance imaging of the pituitary tumor on day 1 (A and B) and day $216(\mathrm{C}$ and $\mathrm{D})$ after the first diagnosis. The presence of pituitary tumor was evaluated using gadodiamide hydrate (Gd)- T1-weighted (T1W) images with transverse (A and C) and sagittal acquisitions (B and D). The pituitary tumor was demonstrated by hyperintense signal of the pituitary area on Gd-T1W images. Before radiation therapy, pituitary tumor was $8.0 \mathrm{~mm}$ in height (A and B), and after radiation therapy, the tumor was $5.0 \mathrm{~mm}$ in height $(\mathrm{C}$ and $\mathrm{D})$.

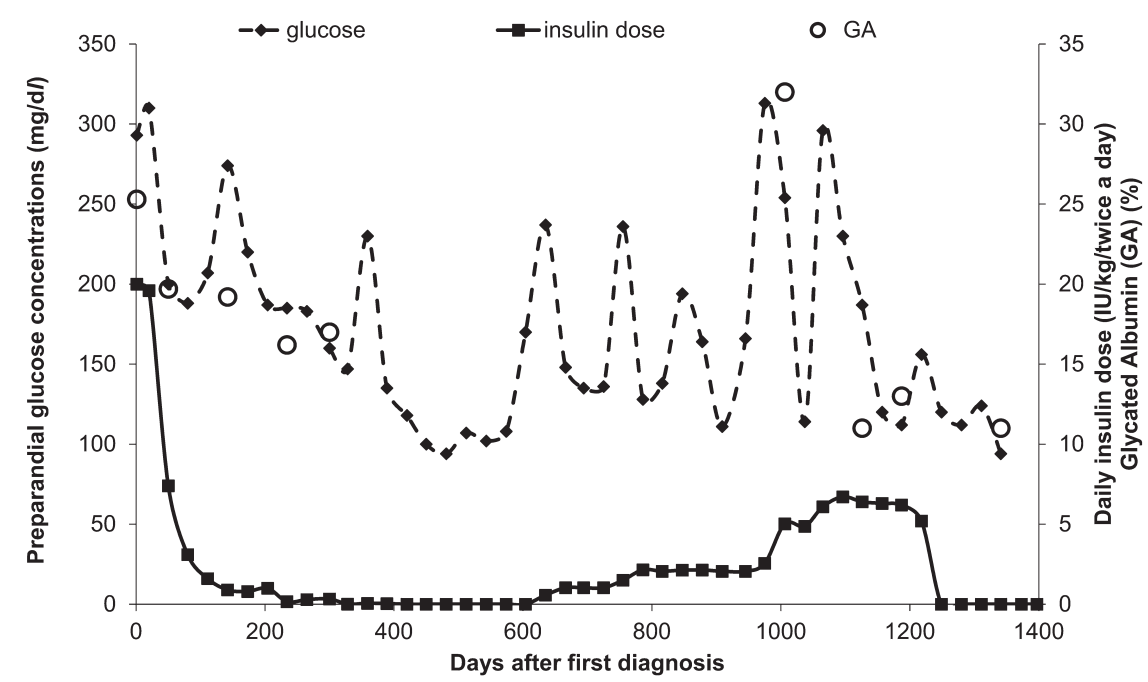

Fig. 3. The change in serum preprandial glucose concentrations ( $\mathrm{mg} / \mathrm{d} l$ ) (left y-axis, dashed line), daily insulin dose (IU/kg twice daily) (right y-axis, solid line), and serum glycated albumin (\%) (right y-axis, open circle) in the cat from day 1 to day $1,397$.

MRI examination on day 1,065. Furthermore, tumor enlargement $(8.0 \mathrm{~mm})$ was observed on day 1,065, and insulin dosage of $6.7 \mathrm{IU} / \mathrm{kg}$ (twice daily) was required on day 1,096 to maintain daily blood glucose concentration of $<300 \mathrm{mg} / \mathrm{d} l$. We regarded the insulin-resistant cause as the re-increase in pituitary gland tumor because there was not a clear cause by blood test and abdominal ultrasound. On day 1,201, a second course of RT was performed with a total of 24 Gy given in 4 fractions (6 Gy each) once a week using the same equipment as described earlier. Blood glucose concentration was normalized after the second course of RT, and 


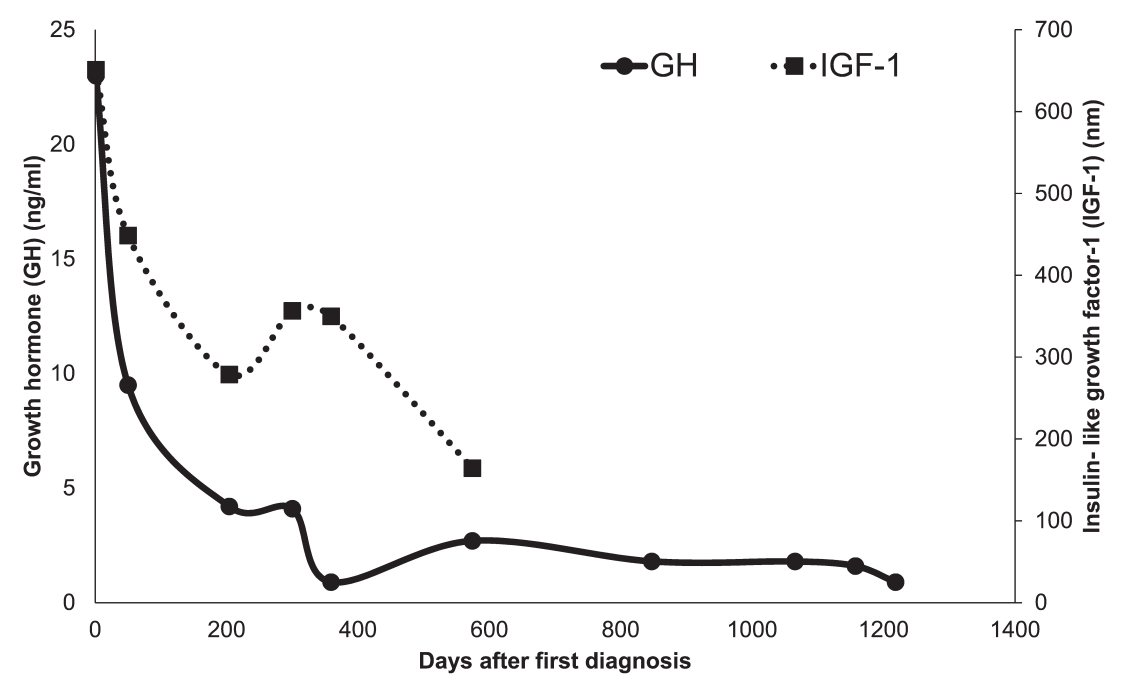

Fig. 4. The change in serum growth hormone $(\mathrm{GH})(\mathrm{ng} / \mathrm{m} l)$ (left $\mathrm{y}$-axis, solid line) and serum insulin-like growth factor-1 (IGF-1) concentrations (nm) (right y-axis, dashed line) in the cat during the disease period.

insulin administration was not required until death. Moreover, MRI examination showed that the tumor had decreased (5.6 mm) on day 1,307. At approximately 1,350 days, the cat exhibited anorexia, vomiting, diarrhea, lethargy, and ataxia. The cat died on day 1,397 with significant emaciation, persistent diarrhea, anisocoria, and tachypnea, and postmortem examination was performed on the same day. Macroscopic findings revealed no abnormal finings of brain. However, enlargement of the pancreas, mesenteric, porta hepatis, superficial cervical and mediastinal lymph nodes was detected. The pituitary tumor cells had small, round, hyperchromatic nuclei with abundant eosinophilic cytoplasm (Fig. 5A). Most tumor cells were positive for chromogranin A, synaptophysin, and GH immunohistochemistry (Fig. 5B), but were negative for ACTH, FSH, LH, and TSH. There was no pathological abnormality in the brain. Interestingly, the pancreatic acinar cells were normal, and the pancreatic islet cells revealed diffuse hyperplasia (Fig. 5C). Other regions included gastrointestinal lymphoma (liver, spleen, jejunum, ileum and mesenteric, porta hepatis, pancreatic, superficial cervical and mediastinal lymph nodes) with large cell type (high-grade type), which is considered a major cause of mortality.

In this case report, acromegaly was diagnosed by elevated serum GH and IGF-1 concentrations as well as an enlarged pituitary tumor $[5,6,13]$. Excess GH secretion induces severe insulin resistance by stimulating IGF-1 production; therefore, IGF-1 secretion may reflect $\mathrm{GH}$ production in the previous $24 \mathrm{hr}$ [15].

Some case studies with feline acromegaly treated with RT have reported reduced GH concentration [6, 7], which were similar to the results in our case after the first course of RT. Meanwhile, increased GH concentration was not observed the day after insulin administration was resumed (days $847,1,065,1,157$, and 1,218). Our study evaluated serum GH concentrations with a single measurement; however, a single measurement of GH concentration is not diagnostic for acromegaly as it may be the result of a secretory pulse [6]. It is currently recommended to collect 3-5 samples for GH concentration measurement at 10-min intervals [6]. Consequently, unchanged GH concentration after day 635 (resumed insulin administration) might be a false result due to GH secretory pulse.

IGF-1 is not secreted in pulses, and its concentration is constant throughout the day; therefore, IGF-1 concentration should be measured at the first diagnosis of acromegaly [6]. In our case, serum IGF-1 concentration gradually decreased after the first course of RT. However, one study reported that IGF-1 concentration remained elevated at 6 and 10 months following RT [9]. Furthermore, Dunning et al. [4] reported that changes in IGF-1 concentration did not reflect clinical improvement in glycemic control after RT, since pre- and post-RT IGF-1 and fructosamine (glycemic control marker) gave discordant results. Therefore, it does not appear to be helpful to measure IGF-1 concentration after RT as a predictor of diabetes course [6]. In our opinion, IGF-1 concentration should be measured at the first diagnosis of acromegaly. Furthermore, the veterinarian should be aware that the IGF-1 concentration does not always correspond to glycemic status after RT.

A variety of RT protocols for treating feline acromegaly have been reported in the literature [2, 7-10, 16, 19]. Peterson et al. [16] reported that RT (Co-60) with 48 Gy was performed in two acromegalic cats, and Goossens et al. [7] reported that RT (Co-60) with 48 Gy in 12 fractions treated three diabetic acromegalic cats with pituitary tumor. Another study described RT (electrons and photons) treatment of two acromegalic cats with pituitary tumor using 38.5 and 42 Gy given in 11 and 12 fractions (3.5 Gy each), respectively [8]. Brearley et al. [2] treated 12 cats with pituitary tumor using RT (linear accelerator) with 37 Gy given in 5 onceweekly fractions. Modified RT (linear accelerator) was performed in 11 cats with pituitary tumor with a single large dose (15 or 20 Gy) [19]. In our case, we modified the protocol of Goossens et al. [7] with 48 Gy in 12 fractions. Our case have positive outcomes, since length of first emission is over three year. However, optimal radiation protocol for feline pituitary tumor should be further studies. 
A

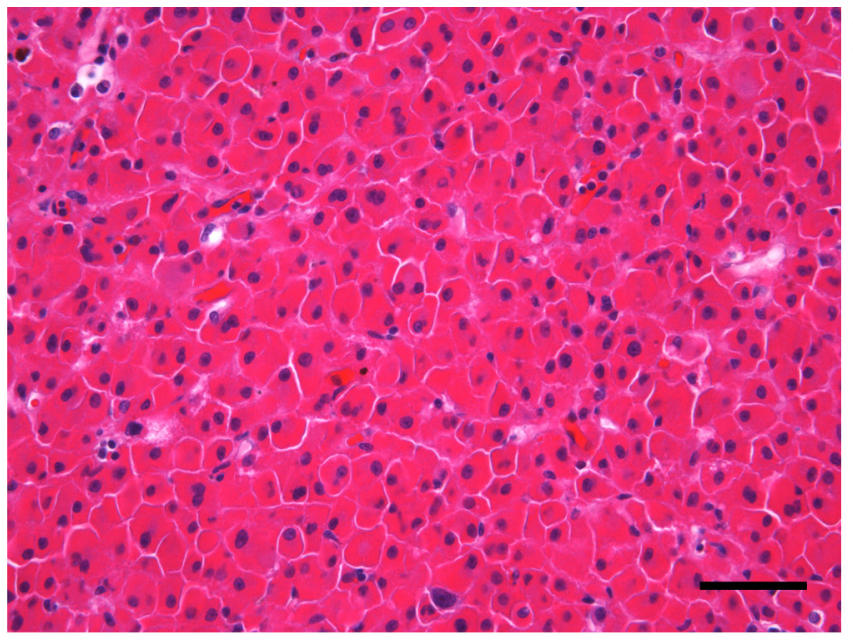

B

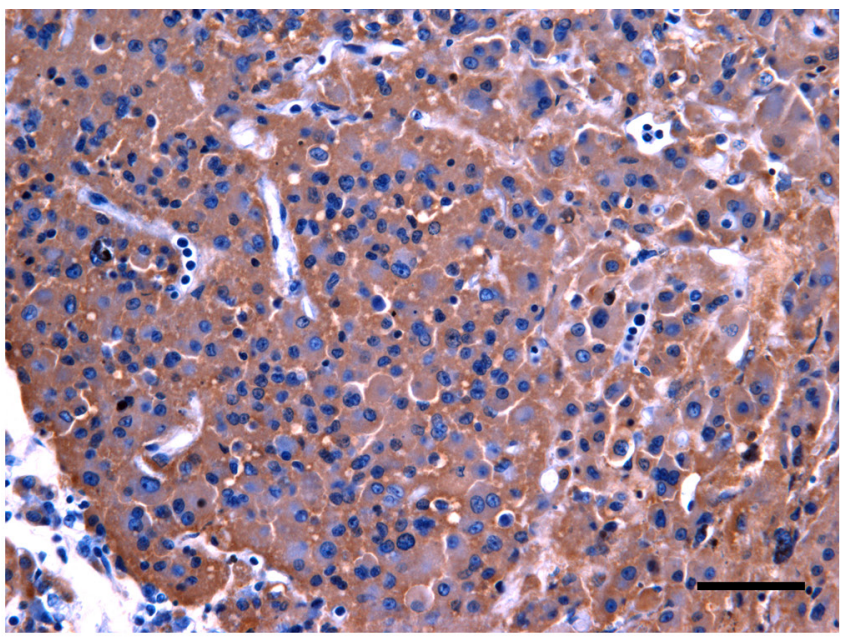

C

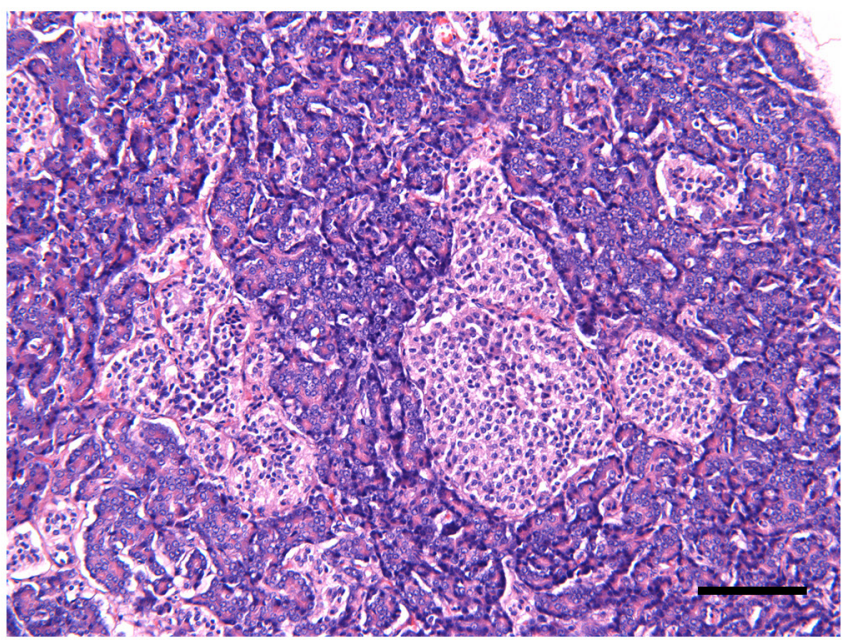

Fig. 5. Histologic features of feline GHoma. The pituitary tumor cells had small, round, hyperchromatic nuclei and abundant eosinophilic cytoplasm. Hematoxylin and eosin. Bar $=50 \mu \mathrm{m}$ (A). Immunohistochemical feature of feline GHoma. The cytoplasm of most tumor cells is positive for GH. Hematoxylin counterstain. Bar $=50 \mu \mathrm{m}(\mathrm{B})$. The pituitary gland was immunostained using a labeled streptavidin-biotin method with primary mouse antibody for ACTH $($ Dako, $\times 200)$ and primary rabbit antibodies for chromogranin A (ImmunoStar, $\times 1,500)$, synaptophysin (Dako, $\times 200)$, GH (ICN Biomedicals, $\times 800)$, follicle-stimulating hormone (FSH, Dako, prediluted), luteinizing hormone (LH, Dako, prediluted), and thyroid-stimulating hormone (TSH, Dako, prediluted). Histologic features of feline pancreatic islet cells revealed diffuse hyperplasia. HE. Bar= $100 \mu \mathrm{m}(\mathrm{C})$.

We performed the second course of RT on day 1,201. In a human study, several study reported re-irradiation protocol in the treatment of pituitary adenomas and primary brain tumor $[18,20,21]$. In a canine study of three dogs, pituitary tumor regrowth or absence of tumor decrease after RT led to re-irradiation of their pituitary tumors [3]. In that study, the total dose for re-irradiation was 18, 21, and $27 \mathrm{~Gy}$, given in 3-Gy fractions over 3 or 4 weeks. Considering the damage to normal brain tissue and late effect of radiation after the first course of RT in our case, the second course of RT should be performed under 4Gy fractions. However, considering the age and condition of the cat and the circumstances of the owner, once a week anesthesia with 24 Gy in 6 Gy RT protocol (4 fractions) was permitted. To our knowledge, this is the first report of two courses of RT with long intervals between each treatment in a cat with recurrent acromegaly. Although serious radiation damages were not observed on postmortem examination of the brain and pituitary gland, the cat in our study died from lymphoma relatively quickly after re-irradiation. As such, radiation brain damage might be occurred if the cat would live more longer. Accordingly, a re-irradiation protocol for feline recurrent pituitary tumor should be further discussed, taking the long-term complications into consideration.

The cat in our case died from gastrointestinal lymphoma regardless of the acromegaly and diabetes mellitus on day 1,397. Pituitary adenoma was diagnosed with GH-producing pituitary adenoma (GHoma), and our pathology report partially agreed with other reports of isolated pituitary tumors treated by hypophysectomy $[1,11]$. Surprisingly, severe insulin resistance did not irreversibly damage the pancreatic beta cells (only hyperplasia in the pancreatic islet was observed). The general pathological findings in diabetic cats ( $>90 \%$ of cats) are islet amyloidosis associated with pancreatic beta cell loss [14]. We found that normal or hyperfunction of pancreatic beta cells in an acromegalic cat induced remission of insulin administration after RT. Further studies are required to investigate why loss of pancreatic beta cells did not occur. 
In conclusion, we achieved long-term successful management of an acromegalic cat with two courses of RT. The first course reduced GH and IGF-1 concentrations, ameliorating insulin sensitivity and leading to decreased insulin requirement. The second course of RT also led to remission of insulin requirement. Furthermore, postmortem examination of the cat revealed pituitary GHoma and hyperplasia of pancreatic islets. However, a protocol for a second course of RT for feline recurrent pituitary tumor should be further discussed.

\section{REFERENCES}

1. Blois, S. L. and Holmberg, D. L. 2008. Cryohypophysectomy used in the treatment of a case of feline acromegaly. J. Small Anim. Pract. 49: 596-600. [Medline]

2. Brearley, M. J., Polton, G. A., Littler, R. M. and Niessen, S. J. 2006. Coarse fractionated radiation therapy for pituitary tumours in cats: a retrospective study of 12 cases. Vet. Comp. Oncol. 4: 209-217. [Medline] [CrossRef]

3. de Fornel, P., Delisle, F., Devauchelle, P. and Rosenberg, D. 2007. Effects of radiotherapy on pituitary corticotroph macrotumors in dogs: a retrospective study of 12 cases. Can. Vet. J. 48: 481-486. [Medline]

4. Dunning, M. D., Lowrie, C. S., Bexfield, N. H., Dobson, J. M. and Herrtage, M. E. 2009. Exogenous insulin treatment after hypofractionated radiotherapy in cats with diabetes mellitus and acromegaly. J. Vet. Intern. Med. 23: 243-249. [Medline] [CrossRef]

5. Elliott, D. A., Feldman, E. C., Koblik, P. D., Samii, V. F. and Nelson, R. W. 2000. Prevalence of pituitary tumors among diabetic cats with insulin resistance. J. Am. Vet. Med. Assoc. 216: 1765-1768. [Medline] [CrossRef]

6. Feldman, E. C., Nelson, R. W., Reusch, C. E. and Scott-Moncrieff, J. C. R. 2015. Disorders of growth hormone. pp. 37-76. In: Canine and Feline Endocrinology, 4th ed. (Feldman, E. C., Nelson, R. W., Reusch, C. E. and Scott-Moncrieff, J. C. R. eds.), Elsevier Saunders, St. Louis.

7. Goossens, M. M., Feldman, E. C., Nelson, R. W., Theon, A. P., Koblik, P. D., Elliott, D. A. and Rutteman, G. R. 1998. Cobalt 60 irradiation of pituitary gland tumors in three cats with acromegaly. J. Am. Vet. Med. Assoc. 213: 374-376. [Medline]

8. Kaser-Hotz, B., Rohrer, C. R., Stankeova, S., Wergin, M., Fidel, J. and Reusch, C. 2002. Radiotherapy of pituitary tumours in five cats. J. Small Anim. Pract. 43: 303-307. [Medline] [CrossRef]

9. Littler, R. M., Polton, G. A. and Brearley, M. J. 2006. Resolution of diabetes mellitus but not acromegaly in a cat with a pituitary macroadenoma treated with hypofractionated radiation. J. Small Anim. Pract. 47: 392-395. [Medline] [CrossRef]

10. Mayer, M. N., Greco, D. S. and LaRue, S. M. 2006. Outcomes of pituitary tumor irradiation in cats. J. Vet. Intern. Med. 20: 1151-1154. [Medline] [CrossRef]

11. Meij, B. P., Auriemma, E., Grinwis, G., Buijtels, J. J. and Kooistra, H. S. 2010. Successful treatment of acromegaly in a diabetic cat with transsphenoidal hypophysectomy. J. Feline Med. Surg. 12: 406-410. [Medline] [CrossRef]

12. Mori, A., Lee, P., Mizutani, H., Takahashi, T., Azakami, D., Mizukoshi, M., Fukuta, H., Sakusabe, N., Sakusabe, A., Kiyosawa, Y., Arai, T. and Sako, T. 2009. Serum glycated albumin as a glycemic control marker in diabetic cats. J. Vet. Diagn. Invest. 21: 112-116. [Medline] [CrossRef]

13. Norman, E. J. and Mooney, C. T. 2000. Diagnosis and management of diabetes mellitus in five cats with somatotrophic abnormalities. J. Feline Med. Surg. 2: 183-190. [Medline] [CrossRef]

14. O'Brien, T. D. 2002. Pathogenesis of feline diabetes mellitus. Mol. Cell. Endocrinol. 197: 213-219. [Medline] [CrossRef]

15. Peacey, S. R. and Shalet, S. M. 2001. Insulin-like growth factor 1 measurement in diagnosis and management of acromegaly. Ann. Clin. Biochem. 38: 297-303. [Medline] [CrossRef]

16. Peterson, M. E., Taylor, R. S., Greco, D. S., Nelson, R. W., Randolph, J. F., Foodman, M. S., Moroff, S. D., Morrison, S. A. and Lothrop, C. D. 1990. Acromegaly in 14 cats. J. Vet. Intern. Med. 4: 192-201. [Medline] [CrossRef]

17. Rosenfeld, R. G., Wilson, D. M., Dollar, L. A., Bennett, A. and Hintz, R. L. 1982. Both human pituitary growth hormone and recombinant DNAderived human growth hormone cause insulin resistance at a postreceptor site. J. Clin. Endocrinol. Metab. 54: 1033-1038. [Medline] [CrossRef]

18. Schoenthaler, R., Albright, N. W., Wara, W. M., Phillips, T. L., Wilson, C. B. and Larson, D. A. 1992. Re-irradiation of pituitary adenoma. Int. J. Radiat. Oncol. Biol. Phys. 24: 307-314. [Medline] [CrossRef]

19. Sellon, R. K., Fidel, J., Houston, R. and Gavin, P. R. 2009. Linear-accelerator-based modified radiosurgical treatment of pituitary tumors in cats: 11 cases (1997-2008). J. Vet. Intern. Med. 23: 1038-1044. [Medline] [CrossRef]

20. Veninga, T., Langendijk, H. A., Slotman, B. J., Rutten, E. H., van der Kogel, A. J., Prick, M. J., Keyser, A. and van der Maazen, R. W. 2001. Reirradiation of primary brain tumours: survival, clinical response and prognostic factors. Radiother. Oncol. 59: 127-137. [Medline] [CrossRef]

21. Verma, J., McCutcheon, I. E., Waguespack, S. G. and Mahajan, A. 2014. Feasibility and outcome of re-irradiation in the treatment of multiply recurrent pituitary adenomas. Pituitary 17: 539-545. [Medline] [CrossRef] 